\title{
Strategic Identification of Unsafe Actions That Characterize Accidents on Ships
}

\author{
† Haryanti RIVAI - Masao FURUSHO*
}

+ Dept. Naval Architect, Hasanuddin University, Makassar, 90245 Sulawesi Selatan, Indonesia

* Graduate School of Maritime Sciences, Kobe University, Kobe 658-0022, Japan

\begin{abstract}
Seafarers are one of the main engines driving economic growth in the maritime sector. The International Maritime (IMO) Organization estimated that there were approximately 1.5 million seafarers around the world engaged in international trade in 2012. Data have shown that human casualties in maritime accidents around Japan have shown an increasing trend over the last ten years. One cause is human error, which is inseparable from the human element that influences mariner's decisions and actions. The Personal Identification (PIN) Safe method is one way to systematically identify substandard and unsafe actions by considering the error taxonomies associated with various scenarios for a maritime system. The results are based on analysis of the role of the human element in commonly reported unsafe actions when interacting with equipment and other systems. Furthermore, patterns of influencing shaping factors were observed on the basis of data processing; the aim of this study was to promote safety culture and provide an opportunity to improve safety at sea.
\end{abstract}

Key words : maritime accident, human errors, unsafe actions, safety culture, safety at sea, technical failure, PINSafe

\section{INTRODUCTION}

\subsection{Background}

Seafarers are one of the engines driving economic growth in the maritime sector. The International Maritime Organization (IMO) estimated that there were around 1.5 million seafarers around the world serving in international trade in 2012. Data collected by the Marine Accident Inquiry Agency (MAIA) have shown that human casualties in maritime accidents around Japan have shown an increasing trend over the last ten years (figure 1).

Marine accidents have increased with the number of ships. They are known to be caused by human, environmental, and technical factors. Human errors is inseparable from the human element that influences mariner's decisions and actions. Improving the performance of a seafarer is one of the most important tasks in ensuring safety at sea. The number of qualified sailors has not kept pace with the increasing number of ships. A look at maritime casualties reveals that $96 \%$ of all accidents can be attributed to the human element (MAIB, 1991; UK P \& I Club, 1999; Grime, 1996); a study concluded that 60\% of all accidents are directly caused by human error, whereas a further $30 \%$ of accidents are indirectly caused by human error. Thus, the human element has a strong impact on maritime accidents. Therefore, improving the living conditions on ships and ensuring the competence and qualifications of the crew are important to maritime safety.

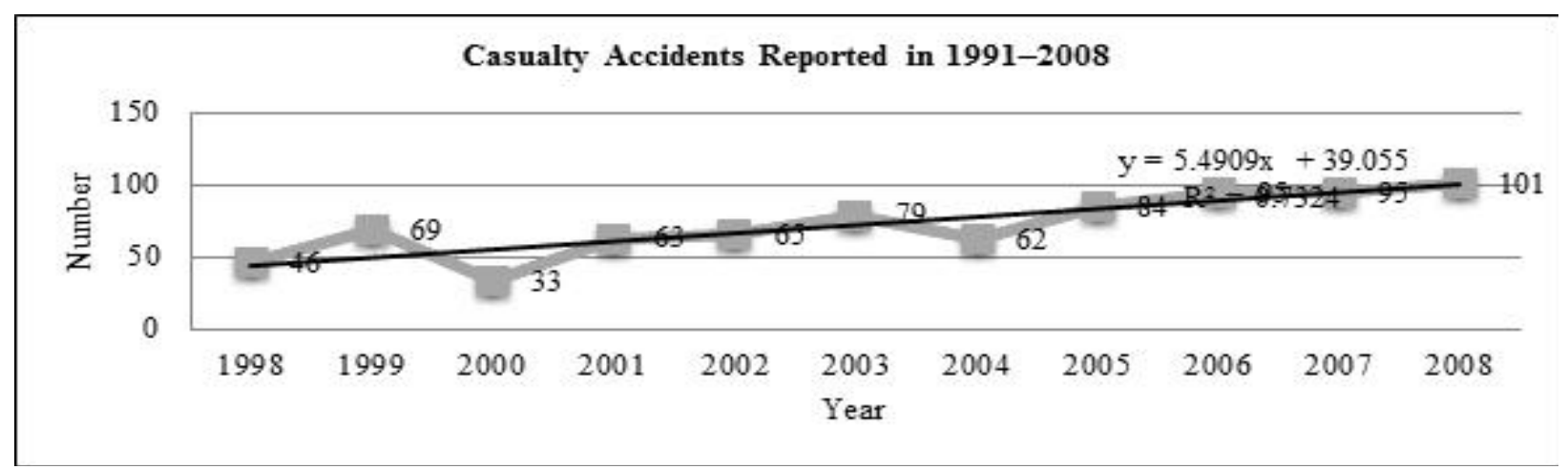

Fig. 1 Casualty accidents reported in $1991-2008$

\footnotetext{
† Corresponding author, haryantirivai@gmail.com
} 


\subsection{Objectives}

The objective of this study was to analyze new methods to pinpoint unsafe actions attributable to the human element. The role played by human element interactions can be used to systematically identify substandard and unsafe actions. The Personal Identification (PIN) Safe method uses error taxonomies associated with typical scenarios conditions on a ship to find patterns of unsafe actions. The results of this analysis can hopefully be used to improve the safety culture at sea.

\section{SCOPE OF ACCIDENTS}

\subsection{Unsafe actions leading to accident}

The investigator starts with the immediate actions and events surrounding the incident and then works backwards to uncover contributing causes (Rothblum et al, 2002). In terms of human errors, those immediately linked to the incident are typically "unsafe actions." There are two types of unsafe actions: errors and violations. Errors represent the mental and physical activities of individuals who fail to achieve their intended outcome, that is, the results of the person's action are not as expected. On the other hand, a violation is when the person's action reflects a willful disregard for standard operating procedures or regulations (even though they probably did not intend to cause an incident).

The principle focus of post-accident (or post-catastrophe) investigations has been on performance failures that immediately preceded an accident. These are termed active failures: human error or violations having an immediate impact on the integrity of a system and others. However, the scope of accident inquiries has widened considerably to also include latent failures committed during the design, management, and organization. Single failures are common. Improvements to the interaction between human operators and the technology used in maritime transport systems have to be considered.

A conditioned response is the behavior of a body to a process occurring owing to the effect of some antecedent

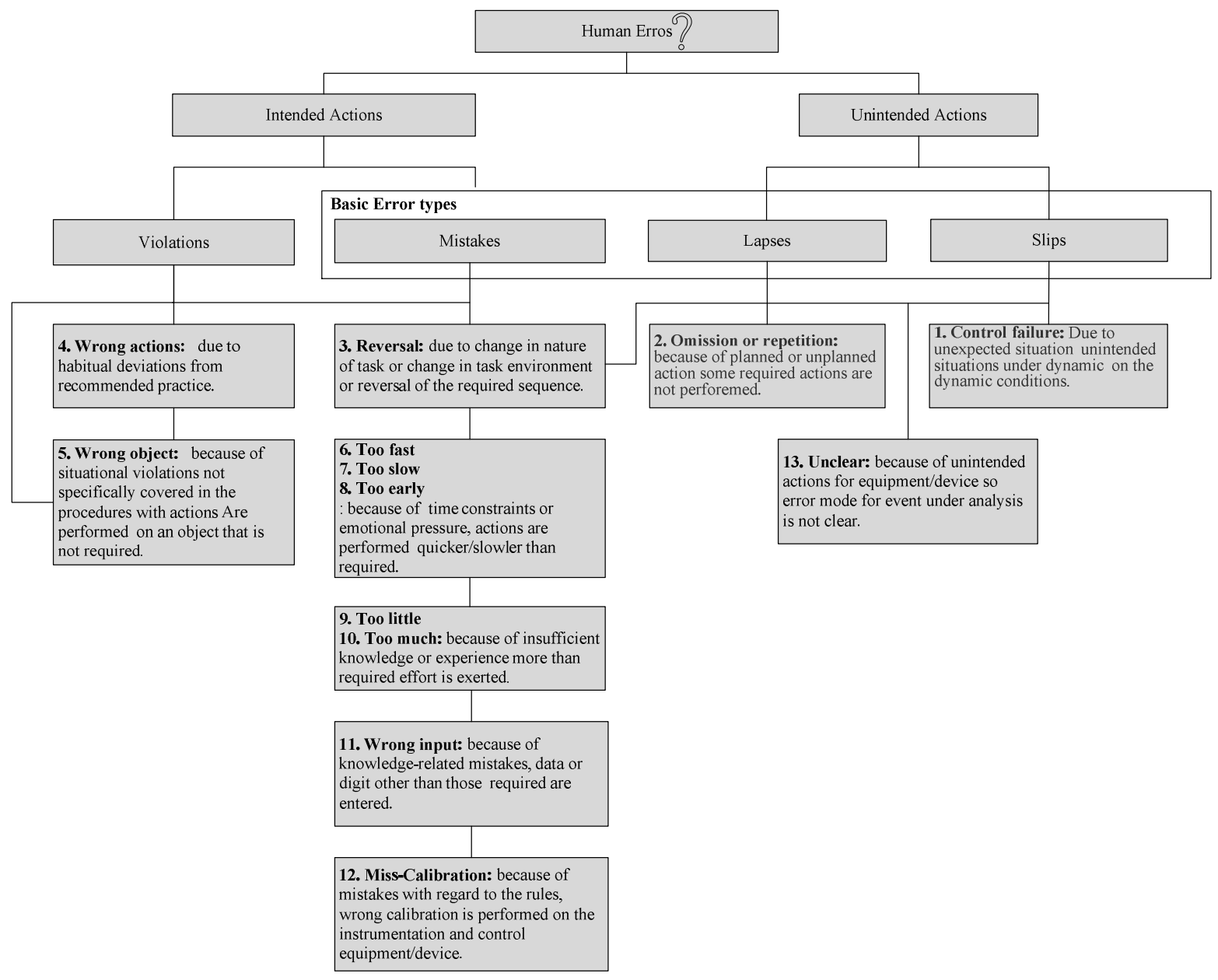

Fig. 2 Error taxonomies (UK P \& I Club,1999) 
stimulus or agent from a system condition. The information is processed in the system memory depending on the condition of the body. Every person has a different perception of a given condition or situation. Generally, a dynamic situation makes decisions and actions quite difficult. Analysis of a subject needs to be comprehensive when a classification system or taxonomy is used as a way to organize knowledge. Hollnagel (1998) proposed a cognitive reliability and error analysis method (CREAM) for error taxonomy, and Grech et al. (2008) used ten of the twenty-two modes of CREAM. Rivai et al. (2011) also used this method for error taxonomy. Taxonomies that emphasize observable behaviors are of practical value. The UK P \& I Club (1999) determined error taxonomies by using the following code to classify errors on the basis of the information processing stage: $1=$ control failure; $2=$ omission or repetition; $3=$ reversal; $4=$ wrong action; $5=$ wrong object; 6 = too fast; 7 = too slow; $8=$ too early; $9=$ too little; 10 = too much; $11=$ wrong input; $12=$ miss-calibration; and 13 = unclear (figure 2).

\subsection{Human element in maritime transport systems}

The maritime transport system is a very complex and large-scale socio-technical environment system consisting of human actions that interact with each other and operate in a physical environment. The main elements of the system are objects of transport, infrastructure, and facilities; these are linked by an information system and transport-related activities (Zhejiang, 2001). The human element is very important: it designs, develops, builds, operates, manages, regulates, and interacts with other elements of the system. These elements are embedded in very complex, interdependent, and dynamic relationships. The IMO assembly adopted resolution A.850(20), which defined the "human element" as "a complex multidimensional issue that affects maritime safety and marine environmental protection" that "involves the entire spectrum of human activities performed by a ship's crew, shore-based management, regulatory bodies, recognized organizations, shipyards, legislators, and other relevant parties." This means that the human element is a component of a system.

The maritime system is a system composed of people (figure 2). Technology-human interactions include perception, decision-making, and performance; humanenvironment interconnections include physical and mental performance, fatigue, and risk taking; and human organization interconnections include fatigue, knowledge, skill, and work practices. In this system, people (man) include the captain, navigator, crew, pilots, dockworkers, vessel traffic service (VTS) officer, operators, and quarantine, customs, and immigration officers. Human technology (machine) interconnections include the ship design and equipment; these may impact people's performance and perception. Human -environment (media) interconnections include the weather, geography, physical work environment, and regulatory and economic climates. Human - organization (management) interconnections include crew organization, company policies, and regulatory governance. Each system structure has its own characteristics

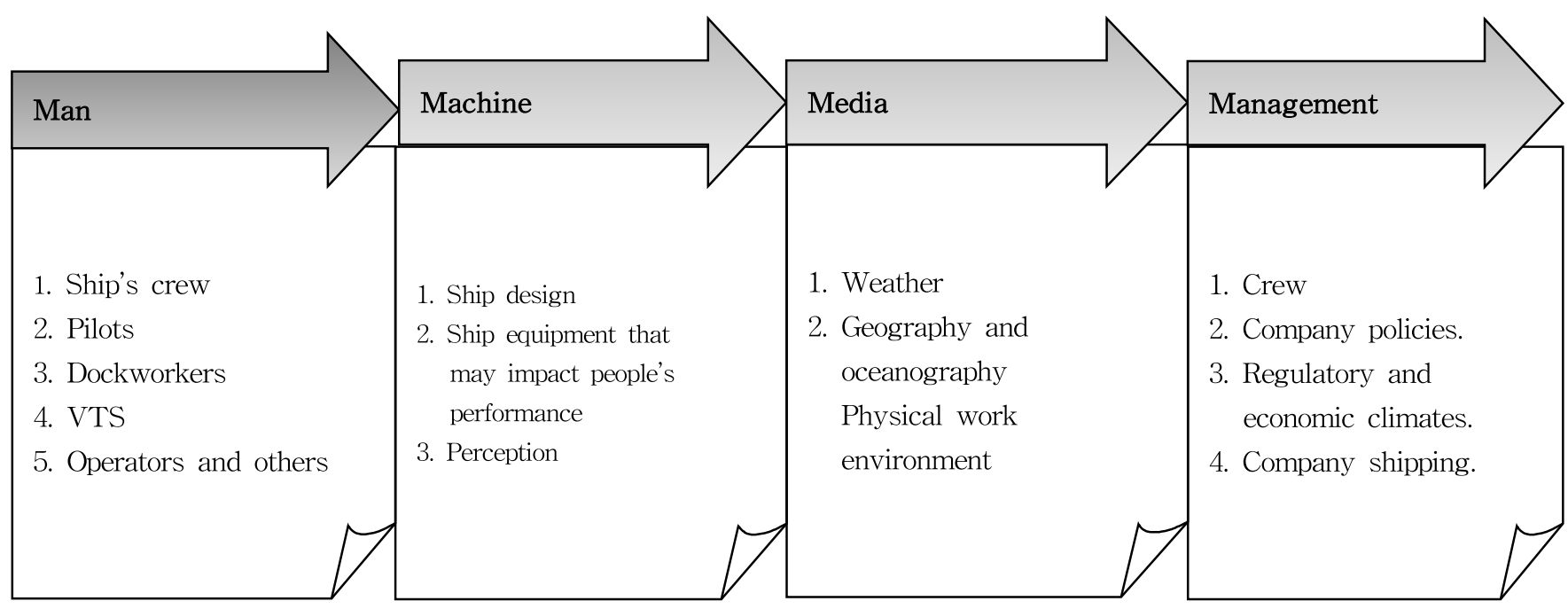

Fig. 3 4M (man, machine, media, and management) relations in maritime system 


\section{METHODS}

\subsection{PINSafe in analysis scenario}

PINSafe is a strategy to identify unsafe actions and critical events associated with characteristic accidents on a ship. A comprehensive PINSafe should be able to eliminate or control unsafe acts during the lifetime of a ship. Both engineering and management solutions, especially the creation of databases to control process parameters, should be considered. Details on PINSafe involve how technical human, and external failures lead to undesired events.

Figure 3 shows one causation model, which can be referred to as the root cause of an accident or incident. The key is to understand the kind of barriers that are needed to contain the propagation of an unwanted event. The far right side of Fig. 1 shows the barriers against undesired events. The model shows that the basic initiation of any undesired event is a technical, human, or external failure or a combination thereof. Humans are the weakest link in any engineering system (Kariuki et al., 2007). This is because

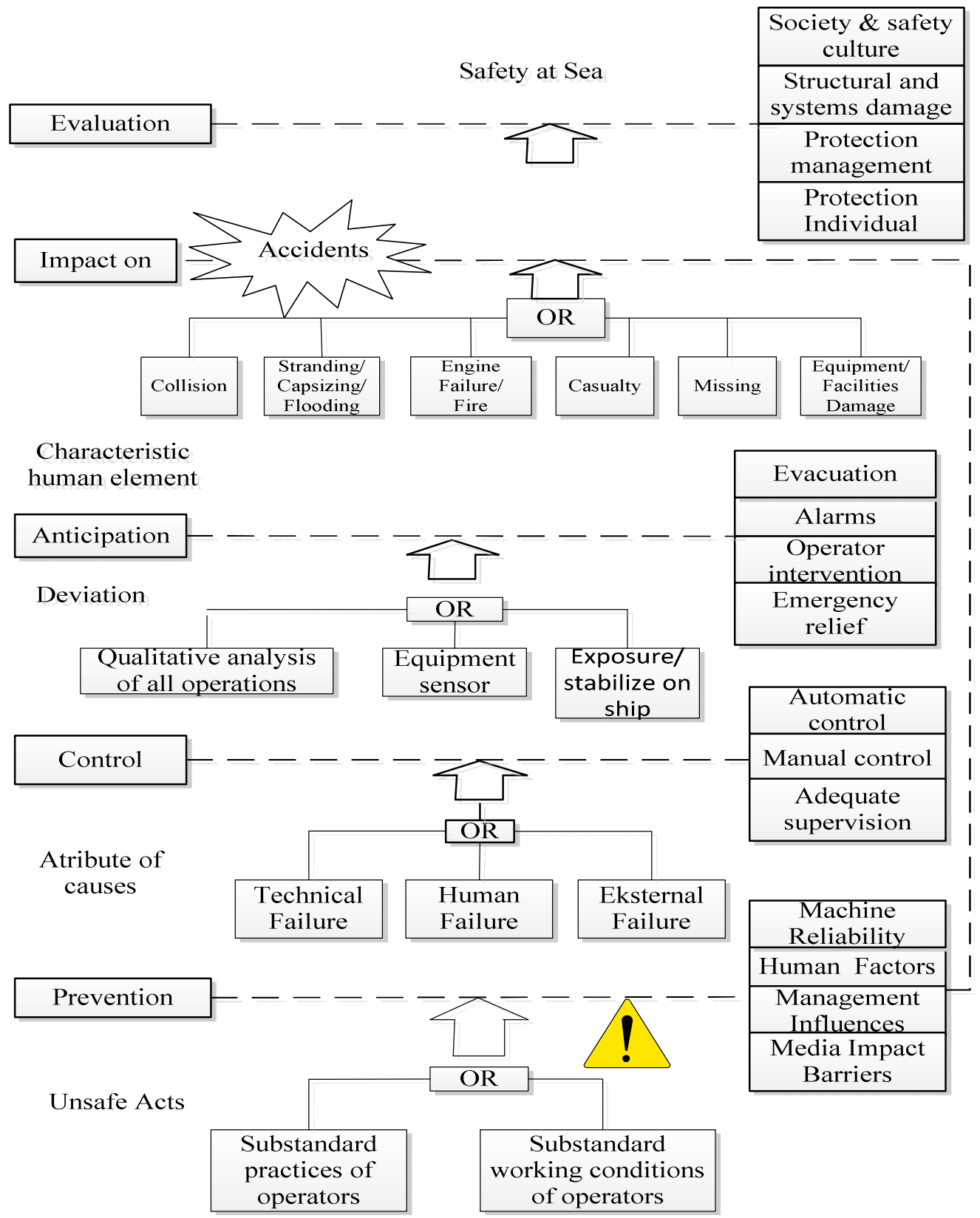

Fig. 4 PINSafe strategy for maritime transport system 
all engineering systems rely on human intervention in some aspect. However, many methods do not give human failure the weight it deserves as a major contributor to unwanted events. Human failure is more complex than just a single operator action. To address human failure comprehensively, a broader perspective of onboard processes should be considered, including management, procedures, training, and other factors that affect base errors.

It is critical to exhaustively identify all the potential underlying causes of major unsafe actions that can be attributed to the failures of the human operator.

\subsection{Evaluation of PINSafe in analysis scenario}

Critical events are consequences that potentially lead to accidents. Every accident that occurs during interaction with the human element will have its own characteristics. These characteristics need to be determined for evaluation by management. Identifying and analyzing the consequences are important to establishing evaluation strategies. Analyzing combinations of individual protection, management protection, structural calculations, and system damage, and their effects on safety culture can provide opportunities to enhance safety at sea. In previous studies, many qualitative models have been used to analyze the risks of accidents or incidents, such as Bayesian models of plan recognition (Charniak, 1992), taxonomy reliability (Ross et al, 2003), and risk-based approaches in CREAM (Marseguerra et al., 2007). PINSafe is a method to qualitatively recognize patterns in human performance by processing error taxonomy information from analysis of unsafe actions within a scenario or root cause. A typical PINSafe comprises the following:

Finite model theory (Istiarto,2013) with sample $\mathrm{S}$ gives the group a real number with a value of $0-1$ that is called weighting or probability; this allows the odds of the occurrence of an event to be calculated

- Each sample point in the sample universe is given a value denoting its probability; the sum of all probabilities for all sample points is equal to 1 .

- To calculate the odds for event A, all the events that make up sample A are added together. $\mathrm{A}$ is the number of these probabilities, which is denoted by $\mathrm{P}(\mathrm{A})$. Thus, the probability set $\varnothing$ is 0 , and $\mathrm{S}$ is 1 .

$$
\begin{aligned}
& 0 \leq \mathrm{P}(\mathrm{A}) \leq 1 \\
& \mathrm{P}(\varnothing)=0 \\
& \mathrm{P}(\mathrm{S})=1
\end{aligned}
$$

- When an experiment has $\mathrm{N}$ different experimental results, each has the same possibility of occurrence, and $\mathrm{n}$ is all of the results of this experiment that contain event $\mathrm{A}$, the probability of event $\mathrm{A}$ is

$$
\mathrm{P}(\mathrm{A})=n / N
$$

The next step of the compound set events is as follows:

- The compound set events are for a combination of two events. If $\mathrm{A}$ and $\mathrm{B}$ are two sets in a universe or sample $\mathrm{S}$, then the union of $\mathrm{A}$ and $\mathrm{B}$ is a new set that consists of members of $\mathrm{A}$ and $\mathrm{B}$ (see equation 5 ):

$\mathrm{A} \cup \mathrm{B}=\{\mathrm{x} \in \mathrm{S} \mid \mathrm{x} \in \mathrm{A}$ or $\mathrm{x} \in \mathrm{B}\}$

Venn Diagram

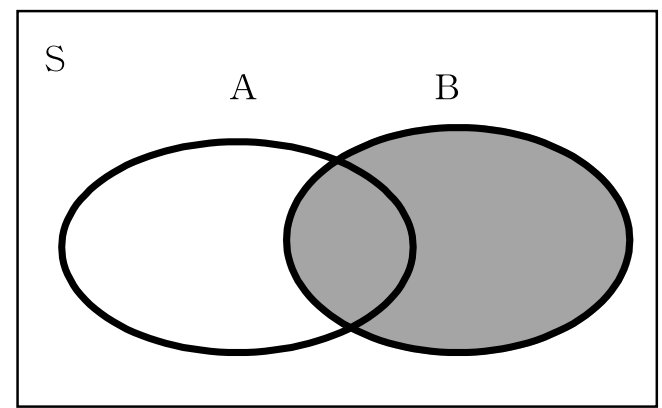

\section{PINSAFE ANALYSIS OF MARITIME TRANSPORT SYSTEM}

\subsection{Identification of unsafe actions in analysis scenario}

Human errors immediately linked to the incident are typically "unsafe actions." There are two types of unsafe acts: basic errors and violations. In the analyzed data (Rivai et al., 2012; MAIA) for Japan over the period 1998 - 2008, 29 of 9716 cases were described as unsafe actions (table 1) The unsafe actions listed in table 1 are broken down during analysis to determine the scenario or root cause. The PINSafe method is implemented in qualitative analysis, as shown in section 4.2, to develop a strategy for error taxonomies (see figure 2). The substandard practices of operators are assessed, particularly decisions made without reference to the normal conditions of the system or applicable rules. Decision errors are an activity or behavior that proceeds as intended, yet the plan proves inadequate or inappropriate for the situation. These unsafe actions are performed by individuals who either did not have the appropriate knowledge or simply made a poor choice. Unsafe actions in a given scenario are analyzed as follows: 
Strategic Identification of Unsafe Actions That Characterize Accidents on Ships

Table 1 Unsafe acts by Y1 - Y29 for collision cases from 1998 to 2008 -1

\begin{tabular}{|c|c|c|}
\hline Unsafe Action & Root cause of condition & $\begin{array}{l}\text { Total } \\
\text { cases }\end{array}$ \\
\hline $\begin{array}{l}\text { Improper management for ship } \\
\text { operations (Y1) }\end{array}$ & Communication is important during operation. & 66 \\
\hline $\begin{array}{l}\text { Poor repair conditions of ship } \\
\text { structure (Y2) }\end{array}$ & Less detailed checks and trials of applicable ship parts to identify problems. & 15 \\
\hline Poor preparation for sea (Y3) & $\begin{array}{l}\text { Knowing the times of the tide and obtaining an up-to-date weather forecast } \\
\text { (especially expected wind conditions). }\end{array}$ & 9 \\
\hline $\begin{array}{l}\text { Improper hydrographic survey before } \\
\text { sailing (Y4) }\end{array}$ & $\begin{array}{l}\text { The work of a hydrographic survey technician can be broken down into several } \\
\text { main job functions. Within each category, there are a series of various tasks that } \\
\text { must be performed. }\end{array}$ & 39 \\
\hline Poor course selection (Y5) & $\begin{array}{l}\text { A seaman selecting and maintaining a ship's course must consider the time, } \\
\text { discipline, money, appropriate technical knowledge and skills, and equipment } \\
\text { support. }\end{array}$ & 67 \\
\hline Improper ship handling (Y6) & $\begin{array}{l}\text { Ship handling in confined waters, particularly narrow waterways, has received a } \\
\text { great deal of attention. }\end{array}$ & 199 \\
\hline Unconfirmed ship position (Y7) & The basics of navigation as commonly practiced by every sailor. & 127 \\
\hline Improper lookout (Y8) & Every vessel shall maintain a proper lookout by sight and hearing at all times. & 4685 \\
\hline Fatigue (Y9) & $\begin{array}{l}\text { The combination of wind and waves can cause sea sickness, which affects motor } \\
\text { skills and the ability to think clearly. }\end{array}$ & 370 \\
\hline $\begin{array}{l}\text { Insufficient maintenance and wrong } \\
\text { handling of steering systems and } \\
\text { nautical instruments (Y10) }\end{array}$ & $\begin{array}{l}\text { Generally, little attention is paid to the steering system as long as it does the job } \\
\text { without excess friction or play, but vessels with aged systems need replacement. }\end{array}$ & 14 \\
\hline $\begin{array}{l}\text { Poor attention to meteorology and } \\
\text { oceanography (Y11) }\end{array}$ & $\begin{array}{l}\text { Poor attention to meteorology and oceanography lowers the quality of } \\
\text { meteorological forecast and warning services that support the safety of life and } \\
\text { property at sea (SOLAS). }\end{array}$ & 62 \\
\hline $\begin{array}{l}\text { Improper anchoring and mooring } \\
\text { (Y12) }\end{array}$ & $\begin{array}{l}\text { Generally, improper anchoring and mooring owing to unsafe actions that do not } \\
\text { select good anchorage and drag the anchor. Incorrect anchoring in tidal waters must } \\
\text { be minimized to prevent accidents on a ship. }\end{array}$ & 28 \\
\hline $\begin{array}{l}\text { Inadequate preparation for rough sea } \\
\text { (Y13) }\end{array}$ & $\begin{array}{l}\text { It is very important for a seafarer to know what to do in rough weather so that } \\
\text { mistakes can be avoided when quick decisions need to be made; the ship can be } \\
\text { prepared for rough sea by taking precautions such as steering control and } \\
\text { machinery control. }\end{array}$ & 9 \\
\hline $\begin{array}{l}\text { No indication of navigation lights and } \\
\text { shapes (Y14) }\end{array}$ & $\begin{array}{l}\text { Navigation aids are lighted whenever necessary; their application involves the } \\
\text { exercise of special skills and fine techniques, which can be perfected only through } \\
\text { experience and careful practice. }\end{array}$ & 189 \\
\hline Signaling failure (Y15) & $\begin{array}{l}\text { Refers to improperly interpreting relevant signals from the ship whistle when } \\
\text { making maneuvers. }\end{array}$ & 895 \\
\hline Improper ship speed (Y16) & $\begin{array}{l}\text { Every vessel shall at all times proceed at a safe speed to take proper and effective } \\
\text { action to avoid collision and stop within a distance appropriate to the prevailing } \\
\text { circumstances and conditions. }\end{array}$ & 351 \\
\hline Not obeying COLREG (Y17) & $\begin{array}{l}\text { Not obeying Collision Regulation (COLREGs) can be put down to misinterpretation, } \\
\text { even though the rules are quite clear. }\end{array}$ & 1683 \\
\hline Main engine failure (Y18) & $\begin{array}{l}\text { Main engine failure is generally due to a lack of cylinder overhauling, which means } \\
\text { lapses in the routine maintenance of the marine diesel engine to ensure that the } \\
\text { components are not excessively worn and are fit to continue service. }\end{array}$ & 10 \\
\hline Auxiliary engine failure (Y19) & $\begin{array}{l}\text { Primary engine failure requires troubleshooting the marine auxiliary diesel engine. } \\
\text { Improper maintenance damages the machine or system, which affects the } \\
\text { operational system that is not runing and triggers failures such as fire. }\end{array}$ & 22 \\
\hline $\begin{array}{l}\text { Poor management of lubricant oil } \\
\text { (Y20) }\end{array}$ & $\begin{array}{l}\text { Proper practices and procedures are needed to ensure that standby lubricating oil } \\
\text { filters are available. }\end{array}$ & 5 \\
\hline
\end{tabular}




\begin{tabular}{|c|c|c|}
\hline $\begin{array}{l}\text { Poor management of electrical } \\
\text { equipment (Y21) }\end{array}$ & $\begin{array}{l}\text { A ship steering systems are commonly electrohydraulic; the "electric" parts require } \\
\text { continual checking, testing, and maintenance as all electrical systems on the ship } \\
\text { do. }\end{array}$ & 6 \\
\hline $\begin{array}{l}\text { Improper handling and other tasks } \\
\text { (Y22) }\end{array}$ & $\begin{array}{l}\text { Proper handling and other tasks are largely a matter of common sense and } \\
\text { necessary for the care and protection of objects. Seafarers need to know the } \\
\text { workplace and be trained in the proper use and limitations of the equipment they } \\
\text { operate. }\end{array}$ & 7 \\
\hline Improper fishing work (Y23) & $\begin{array}{l}\text { Practical understanding of the basic types of small fishing vessels, including } \\
\text { common terminology, is required. A fishing vessel encumbered by her nets or trawl } \\
\text { cannot keep out of the way of other vessels; Rule } 26 \text { directs all other vessels to } \\
\text { keep out of the way of fishing vessels. }\end{array}$ & 0 \\
\hline $\begin{array}{l}\text { Poor management of passenger and } \\
\text { cargo loading (Y24) }\end{array}$ & $\begin{array}{l}\text { Recognizing that actions taken when containers are stuffed may have direct } \\
\text { implications on the stability and safety of container ships, the lives of seafarers on } \\
\text { the ship, and the safety of others throughout the transport chain is of utmost } \\
\text { importance. }\end{array}$ & 2 \\
\hline $\begin{array}{l}\text { Inadequate supervision of work } \\
\text { onboard (Y25) }\end{array}$ & $\begin{array}{l}\text { Close supervision by qualified experts is of critical importance, starting from a } \\
\text { vessel's inception on the drawing board through its sea trials to final delivery and } \\
\text { continued monitoring during sailing. }\end{array}$ & 571 \\
\hline $\begin{array}{l}\text { Inadequate reporting and taking over } \\
\text { the watch (Y26) }\end{array}$ & $\begin{array}{l}\text { The officer of the watch should not hand the watch over to the relieving officer if } \\
\text { he has a good reason not to do so. }\end{array}$ & 263 \\
\hline Poor fire management (Y27) & $\begin{array}{l}\text { Each scenario is influenced by various factors, not least the nature of the fire and } \\
\text { what is actually burning. In the event of an engine room fire, where the fire is } \\
\text { completely flooded with } \mathrm{CO} 2 \text {, the ship immediately becomes a "dead ship." }\end{array}$ & 0 \\
\hline Force majeure (Y28) & $\begin{array}{l}\text { Force majeure is sometimes called other forces and external forces. Generally, its } \\
\text { unsafe conditions are external and unpredictable. In contrast to unpredictable } \\
\text { situations, nonperformance is caused by usual and natural events. }\end{array}$ & 1 \\
\hline Others (Y29) & & 21 \\
\hline
\end{tabular}

\subsection{Evaluation of PINSafe analysis for error taxonomy}

Any accident that occurs is a union of several events where unsafe actions were taken. An unsafe action is an erroneous decision or action made by a human. Data on unsafe actions were previously recorded by MAIA (see table 1); the data were then analyzed to determine the possible root causes of the unsafe actions in the scenario analysis model. In the PINSafe method, the models take a variety of sources and examine the root causes to overcome the limited data.

The next step is understanding the root causes of unsafe actions in each scenario; the error taxonomy (see figure 2)

presented by the UK P\&I Club was implemented as a sample set (see equation 5) of event probabilities.

In probability theory, the conditions of each human factor that shapes the performance of a seafarer can be implemented as follows:

$$
\mathrm{S}=\{\text { error taxonomy }\}
$$

where $\mathrm{S}$ is the sample universe of human errors:

$$
S=\{1,2,3,4,5,6,7,8,9,10,11,12,13\} \text { (6) }
$$

where 1 - 13 are codes for the error taxonomy (see figure 2) in equation 4.

$\mathrm{N}(\mathrm{S})=13 ; \mathrm{N}$ is the number of members in a sample

Not influenced: $\mathrm{P}\{\mathrm{S}\}=0 / 13$

Influenced: $\mathrm{P}\{\mathrm{S}\}=1 / 13$

The error taxonomy is developed by applying the combined analysis of the root causes of unsafe actions for every incident that has caused onboard accidents. According to the MAIA, one of the most common causes of accidents over the last ten years is collisions. The analysis is as follows:

If $\mathrm{Y} 1$ and $\mathrm{Y} 2$ are two sets in universe $\mathrm{S}$, then the union of $\mathrm{Y} 1$ and $\mathrm{Y} 2$ is a new set whose membership consists of members of $\mathrm{A}$ and $\mathrm{B}$ (see equation 5):

$$
\mathrm{Y} 1 \cup \mathrm{Y} 2=\{\mathrm{x} \in \mathrm{S} \mid \mathrm{x} \in \mathrm{Y} 1 \text { or } \mathrm{x} \in \mathrm{Y} 2\}
$$

Venn Diagram

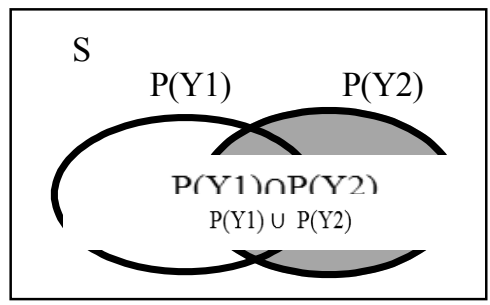


Strategic Identification of Unsafe Actions That Characterize Accidents on Ships

For every event, an unsafe action occurred; the compound set in equation 6 shows the chances of collision accidents on the basis of the probabilities of unsafe actions such as Y1 - Y29 in the error taxonomy (see equations (4) - (6)), as listed in table 2:

Table 2 Counting unsafe actions in error taxonomy

\begin{tabular}{|c|c|c|c|c|c|c|c|c|c|c|c|c|c|c|c|c|}
\hline \multirow{3}{*}{ Unsafe action } & \multicolumn{13}{|c|}{ Taxonomy Error } & \multirow{3}{*}{$\mathrm{n}(\mathrm{Y})$} & \multirow{3}{*}{\begin{tabular}{|c|}
$\mathbf{P}(\mathbf{Y i})=$ \\
$\mathrm{n}(\mathbf{Y i}) / 13 ;$ \\
$\mathrm{i}=\mathbf{1 , 2}, \ldots, 29$ \\
\end{tabular}} & \multirow{3}{*}{ Pattern } \\
\hline & \multicolumn{13}{|c|}{ Code } & & & \\
\hline & 1 & 2 & 3 & 4 & 5 & 6 & 7 & 8 & 9 & 10 & 11 & 12 & 13 & & & \\
\hline $\begin{array}{l}\text { Improper management of ship } \\
\text { operations (Y1) }\end{array}$ & $\mathbf{x}$ & & & $\mathbf{x}$ & & $\mathbf{x}$ & $\mathbf{x}$ & $\mathbf{x}$ & $\mathbf{x}$ & $\mathbf{x}$ & $\mathbf{X}$ & & $\mathbf{x}$ & 9 & $9 / 13$ & \multirow{6}{*}{ A } \\
\hline $\begin{array}{l}\text { Improper hydrographic survey } \\
\text { before sailing (Y4) }\end{array}$ & $\mathbf{x}$ & $\mathbf{x}$ & & $\mathbf{X}$ & $\mathbf{x}$ & & & & $\mathbf{x}$ & $\mathbf{x}$ & $\mathbf{X}$ & $\mathbf{x}$ & $\mathbf{x}$ & 9 & $9 / 13$ & \\
\hline $\begin{array}{l}\text { Poor attention to meteorology and } \\
\text { oceanography (Y11) }\end{array}$ & $\mathbf{x}$ & $\mathbf{x}$ & $\mathbf{x}$ & $\mathbf{x}$ & & $\mathbf{x}$ & $\mathbf{x}$ & $\mathbf{x}$ & & & $\mathbf{x}$ & & $\mathbf{x}$ & 9 & $9 / 13$ & \\
\hline $\begin{array}{l}\text { No indication of navigation lights } \\
\text { and shapes (Y14) }\end{array}$ & $\mathbf{x}$ & & $\mathbf{x}$ & $\mathbf{x}$ & $\mathbf{x}$ & $\mathbf{x}$ & $\mathbf{x}$ & $\mathbf{x}$ & & & $\mathbf{x}$ & & $\mathbf{x}$ & 9 & $9 / 13$ & \\
\hline Main engine failure (Y18) & $\mathbf{X}$ & $\mathbf{X}$ & $\mathbf{X}$ & $\mathbf{X}$ & & $\mathbf{X}$ & $\mathbf{X}$ & $\mathbf{x}$ & & & & $\mathbf{X}$ & $\mathbf{X}$ & 9 & $9 / 13$ & \\
\hline $\begin{array}{l}\text { Improper handling and other tasks } \\
\text { (Y22) }\end{array}$ & $\mathbf{x}$ & $\mathbf{x}$ & $\mathbf{x}$ & & & $\mathbf{x}$ & $\mathbf{x}$ & $\mathbf{x}$ & $\mathbf{x}$ & $\mathbf{x}$ & & & $\mathbf{x}$ & 9 & $9 / 13$ & \\
\hline Poor course selection (Y5) & $\mathbf{x}$ & & & $\mathbf{x}$ & & $\mathbf{x}$ & & & & $\mathbf{x}$ & $\mathbf{x}$ & $\mathbf{x}$ & $\mathbf{x}$ & 7 & $7 / 13$ & \multirow{7}{*}{ B } \\
\hline Unconfimed ship's position (Y7) & $\mathbf{x}$ & $\mathbf{x}$ & $\mathbf{x}$ & & & & & & $\mathbf{x}$ & $\mathbf{x}$ & $\mathbf{x}$ & & $\mathbf{x}$ & 7 & $7 / 13$ & \\
\hline $\begin{array}{l}\text { Improper anchoring and mooring } \\
\text { (Y12) }\end{array}$ & $\mathbf{x}$ & & & $\mathbf{x}$ & $\mathbf{x}$ & & $\mathbf{x}$ & $\mathbf{x}$ & $\mathbf{x}$ & & & & $\mathbf{x}$ & 7 & $7 / 13$ & \\
\hline Improper ship speed (Y16) & $\mathbf{X}$ & & & $\mathbf{X}$ & & $\mathbf{X}$ & $\mathbf{X}$ & $\mathbf{X}$ & & & $\mathbf{X}$ & & $\mathbf{X}$ & 7 & $7 / 13$ & \\
\hline $\begin{array}{l}\text { Poor management of electrical } \\
\text { equipment (Y21) }\end{array}$ & $\mathbf{x}$ & $\mathbf{x}$ & & & & & & & $\mathbf{x}$ & $\mathbf{x}$ & $\mathbf{X}$ & $\mathbf{X}$ & $\mathbf{X}$ & 7 & $7 / 13$ & \\
\hline Improper fishing work (Y23) & $\mathbf{X}$ & & & $\mathbf{X}$ & $\mathbf{X}$ & & & & $\mathbf{X}$ & $\mathbf{X}$ & $\mathbf{X}$ & & $\mathbf{X}$ & 7 & $7 / 13$ & \\
\hline $\begin{array}{l}\text { Inadequate reporting and taking } \\
\text { over the watch (Y26) }\end{array}$ & $\mathbf{x}$ & $\mathbf{x}$ & $\mathbf{x}$ & & & $\mathbf{x}$ & $\mathbf{x}$ & $\mathbf{x}$ & & & & & $\mathbf{x}$ & 7 & $7 / 13$ & \\
\hline $\begin{array}{l}\text { Poor repair condition of ship } \\
\text { construction (Y2) }\end{array}$ & $\mathbf{x}$ & $\mathbf{x}$ & $\mathbf{x}$ & & & $\mathbf{x}$ & $\mathbf{x}$ & $\mathbf{x}$ & & & & $\mathbf{x}$ & $\mathbf{x}$ & 8 & $8 / 13$ & \multirow{5}{*}{$\mathrm{C}$} \\
\hline Poor preparation for sea (Y3) & $\mathbf{x}$ & & $\mathbf{x}$ & $\mathbf{x}$ & $\mathbf{x}$ & & & & $\mathbf{x}$ & $\mathbf{x}$ & & $\mathbf{x}$ & $\mathbf{x}$ & 8 & $8 / 13$ & \\
\hline $\begin{array}{l}\text { Inadequate preparation for rough } \\
\text { seas (Y13) }\end{array}$ & $\mathbf{x}$ & $\mathbf{x}$ & & $\mathbf{x}$ & $\mathbf{x}$ & $\mathbf{x}$ & $\mathbf{x}$ & $\mathbf{x}$ & & & & & $\mathbf{x}$ & 8 & $8 / 13$ & \\
\hline Signaling failure (Y15) & $\mathrm{X}$ & & & $\mathrm{X}$ & & $\mathbf{X}$ & $\mathbf{X}$ & $\mathbf{X}$ & $\mathbf{X}$ & $\mathbf{X}$ & & & $\mathbf{X}$ & 8 & $8 / 13$ & \\
\hline Auxiliary engine failure (Y19) & $\mathbf{X}$ & $\mathbf{X}$ & $\mathbf{X}$ & $\mathbf{X}$ & $\mathbf{X}$ & & & & & & $\mathbf{X}$ & $\mathbf{X}$ & $\mathbf{X}$ & 8 & $8 / 13$ & \\
\hline $\begin{array}{l}\text { Insufficient maintenance and wrong } \\
\text { handling of steering systems and } \\
\text { nautical instruments (Y10) }\end{array}$ & $\mathbf{x}$ & $\mathbf{x}$ & $\mathbf{x}$ & & & & & & & & $\mathbf{x}$ & $\mathbf{x}$ & $\mathbf{x}$ & 6 & $6 / 13$ & \multirow{3}{*}{$\mathrm{D}$} \\
\hline $\begin{array}{l}\text { Poor management of passenger and } \\
\text { cargo loading (Y24) }\end{array}$ & $\mathbf{x}$ & $\mathbf{x}$ & $\mathbf{x}$ & $\mathbf{x}$ & $\mathbf{x}$ & & & & & & & & $\mathbf{x}$ & 6 & $6 / 13$ & \\
\hline $\begin{array}{l}\text { Inadequate supervision of work } \\
\text { onboard (Y25) }\end{array}$ & $\mathbf{x}$ & $\mathbf{X}$ & & & & $\mathbf{x}$ & $\mathbf{x}$ & $\mathbf{x}$ & & & & & $\mathbf{x}$ & 6 & $6 / 13$ & \\
\hline Fatigue (Y9) & $\mathbf{x}$ & $\mathbf{X}$ & $\mathbf{X}$ & $\mathbf{x}$ & $\mathbf{x}$ & $\mathbf{x}$ & $\mathbf{x}$ & & $\mathbf{X}$ & $\mathbf{x}$ & $\mathbf{x}$ & $\mathbf{X}$ & $\mathbf{X}$ & 12 & $12 / 13$ & \multirow{2}{*}{$\mathrm{E}$} \\
\hline Not obeying COLREG (Y17) & $\mathbf{X}$ & $\mathbf{X}$ & $\mathbf{X}$ & $\mathbf{X}$ & $\mathrm{X}$ & $\mathbf{x}$ & $\mathbf{X}$ & $\mathbf{X}$ & $\mathbf{X}$ & $\mathbf{x}$ & & $\mathbf{X}$ & $\mathbf{X}$ & 12 & $12 / 13$ & \\
\hline $\begin{array}{l}\text { Poor management of lubricant oil } \\
\text { (Y20) }\end{array}$ & & & $\mathbf{x}$ & & & & & & $\mathbf{X}$ & $\mathbf{x}$ & & & $\mathbf{x}$ & 4 & $4 / 13$ & \multirow[t]{2}{*}{$\mathrm{F}$} \\
\hline Poor fire management (Y27) & $\mathbf{X}$ & & & $\mathbf{x}$ & $\mathrm{X}$ & & & & & & & & $\mathbf{X}$ & 4 & $4 / 13$ & \\
\hline Improper ship handling (Y6) & $\mathrm{x}$ & & $\mathbf{X}$ & $\mathrm{X}$ & $\mathrm{X}$ & $\mathbf{x}$ & $\mathbf{X}$ & $\mathbf{x}$ & $\mathbf{X}$ & $\mathbf{X}$ & $\mathbf{X}$ & & $\mathbf{x}$ & 11 & $11 / 13$ & \\
\hline Improper lookout (Y8) & $\mathrm{x}$ & $\mathbf{x}$ & & $\mathbf{x}$ & $\mathrm{x}$ & $\mathbf{x}$ & $\mathbf{x}$ & $\mathbf{x}$ & & & $\mathbf{x}$ & $\mathbf{X}$ & $\mathbf{x}$ & 10 & $10 / 13$ & \\
\hline Force majeure (Y28) & $\mathbf{x}$ & & & & & & & & & & & & $\mathbf{x}$ & 2 & $2 / 13$ & \\
\hline Others (Y29) & $\mathbf{x}$ & $\mathbf{x}$ & $\mathbf{x}$ & $\mathbf{x}$ & $\mathrm{x}$ & $\mathbf{x}$ & $\mathbf{x}$ & $\mathbf{X}$ & $\mathbf{X}$ & $\mathbf{x}$ & $\mathbf{x}$ & $\mathbf{x}$ & $\mathbf{x}$ & 13 & 1 & \\
\hline $\begin{array}{l}(\mathrm{P}(\mathrm{Y} 1 \cap \mathrm{Y} 2 \cap \mathrm{Y} 3 \cap \mathrm{Y} 4 \cap \mathrm{Y} 5 \cap \mathrm{Y} 6 \cap \\
\mathrm{Y} 7 \cap \mathrm{Y} 8 \cap \mathrm{Y} 9 \cap \mathrm{Y} 10 \cap \mathrm{Y} 11 \cap \mathrm{Y} 12 \\
\cap \mathrm{Y} 13 \cap \mathrm{Y} 14 \cap \mathrm{Y} 15 \cap \mathrm{Y} 16 \cap \mathrm{Y} 17 \cap \\
\mathrm{Y} 18 \cap \mathrm{Y} 19 \cap \mathrm{Y} 20 \cap \mathrm{Y} 21 \cap \mathrm{Y} 22 \cap \\
\mathrm{Y} 23 \cap \mathrm{Y} 24 \cap \mathrm{Y} 25 \cap \mathrm{Y} 26 \cap \mathrm{Y} 27 \cap \\
\mathrm{Y} 28 \cap \mathrm{Y} 29))\end{array}$ & $\mathbf{x}$ & & & & & & & & & & & & $\mathbf{x}$ & 2 & & \\
\hline
\end{tabular}

$\mathrm{X}=$ influenced one error.

$1=$ control failure; $2=$ omission or repetition; $3=$ reversal; $4=$ wrong action; $5=$ wrong object; $6=$ too fast;

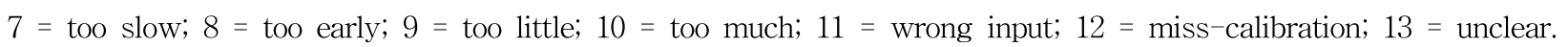




\section{RESULT}

The analysis results determined six patterns from table 2, which are given below:

1. Pattern A had a weight of $9 / 13$ and contained unsafe actions such as improper management (Y1), improper hydrographic survey before sailing (Y4), poor attention paid to meteorology and oceanography (Y11), no indication of navigation lights and shapes (Y14), improper handling and other tasks (Y22), and main engine failure (Y18).

2. Pattern $\mathrm{B}$ had a weight of $7 / 13$ and contained unsafe actions such as poor course selection (Y5), unconfirmed ship position (Y7), improper anchoring and mooring (Y12), improper ship speed (Y16), poor management of electrical equipment (Y21), improper fishing work (Y23), and inadequate report and taking over the watch (Y26).

3. Pattern $\mathrm{C}$ had a weight of $8 / 13$ and contained unsafe actions such as poor preparation for sea (Y3), inadequate preparation for rough seas (Y13), main engine failure (Y18), and auxiliary engine failure (Y19).

4. Pattern D had a weight of $6 / 13$ and contained unsafe actions such as insufficient maintenance and wrong handling of steering systems and nautical instruments (Y10), poor management of passenger and cargo loading (Y24), and inadequate supervision of onboard work (Y25).

5. Pattern E had a weight of $12 / 13$ and contained unsafe actions such as fatigue (Y9) and not obeying COLREG (Y17).

6. Pattern $\mathrm{F}$ had a weight of $4 / 13$ and contained unsafe actions such as poor management of lubricant oil (Y20) and poor management of fire (Y27).

7. Analysis of the error taxonomy found that the root causes of control failure and unclear situations were mostly human error.

\section{CONSIDERATION}

Regarding the results, the following are several considerations:

\section{Machine for technology}

Counteracting pattern A involves developing appropriate technology for human capabilities to mitigate the low visibility and restricted maneuvering of bad weather conditions and narrow waterways in Japan. For identification purposes, lights have individual characteristics in terms of color, intensity, and operation system according to the different perceptions of seafarers.
Counteracting pattern D involves considering ship design problems such as steering, nautical instruments, and control issues for passenger and cargo loading without compromising the safety of the ship. The IMO/ILO/UNECE Guidelines on the Packing of Cargo Transport Units provides a common global resource for information on container stuffing.

\section{Relations of all crew}

Counteracting pattern $\mathrm{B}$ involves improving collaboration by operation arrangements and maintaining interpersonal communications (mental, physical, skill sharing) with other seafarers on the ship.

\section{Management of training}

Counteracting pattern $\mathrm{C}$ involves cooperation between management and seafarers on special issues such as critical situations at sea; moreover, engine conditions should be improved.

\section{Seafarer performance}

Counteracting pattern $\mathrm{E}$ involves maintaining the physical and mental conditions of the seafarers to create a social culture of safety. When the body and mind are fatigued, noncompliance will occur, and rules may not be obeyed. Team cooperation is needed to minimize rule violations. Seafarers should be reminded of the basics of COLREG.

\section{Management of operation}

Counteracting pattern $\mathrm{F}$ involves comprehensive database management technology for the maintenance engine to aid human decisions. The development of monitoring technology for database management will mitigate poor human decisions such as neglecting lubricant oil, which contribute to engine failure. Poor monitoring of lubricant oil prevents moving components from working smoothly; friction would quickly destroy these surfaces and cause engine failure leading to fire. Thus, preventive and corrective maintenance is required.

\section{Keep continuous proper lookout}

Every vessel shall at all times maintain a proper lookout by sight, hearing, and all available means appropriate to the prevailing circumstances and conditions to make a full appraisal of the situation and the risk of collision. Keeping a continuous and proper lookout is an important element of safe watch-keeping, especially when visibility is restricted, 
and includes lookout through hearing, radar, VHF, AIS, and sight.

\section{Design of ship}

Counteracting pattern $\mathrm{D}$ involves mitigating ship design problems such as steering, nautical instruments, and control issues for passenger and cargo loading without compromising the safety of the ship. The IMO/ILO/UNECE Guidelines on the Packing of Cargo Transport Units provides a common global resource for information on container stuffing.

\section{CONCLUSION}

1. All failures involve some kind of deviation from safe operation methods. Unsafe actions or deviations from standard practice is of interest, even though automation and ergonomic design are widely used in other industries. The PINSafe database helps in the determination of error patterns by seafarers for reducing the occurrence of errors.

2. The PINSafe strategy involves processing information on the worker to immediately recognize physical response or unsafe actions to improve cognitive function.

3. The framework for qualitative assessment combines the error taxonomy in the set of a system, which is a union of unsafe actions that have occurred. This method is one way to recognize patterns of unsafe actions.

4. Root cause analysis of the error taxonomy found that control failure and unclear situations are mostly caused by human errors due to unintended actions, which mainly stem from a lack of information or misinformation.

5. In the case of mistakes, the mistaken intention tends to be very resistant to contravening evidence. People tend to ignore feedback information that does not support their expectations of the situation. This is one reason that we need a database to qualitatively assess the attributes of unsafe actions to improve safety culture.

\section{References}

[1] Marine Accident Inquiry Agency of Japan "Statistics of Accidents 1998 - 2008"

[2] Marine Accident Investigation Branch (MAIB), UK (1991) “Annual reports,” London, p. 4.

[3] UK P\&I Club (1999) "Ten-year trends in maritime risk analysis of major claims - a digest," London.

[4] Grime, R..P., Zhao, I., Wilson, P.A., Hu, Z., Wang, F (1996) "Human factors," Proceedings of the International
Conference on Preventing Collision at Sea, Maritime Collision and Prevention 1 pp. 314-329. Epson, Surrey Chiavari Publishing.

[5] A. Rothblum, D. Wheal, S. Withington, S.A. Shappell, D.A. Wiegmann (2002) "Improving incident investigation through inclusion of human factors," United States Department of Transportation-Publications \& Papers 32. http://digitalcommons.unl.edu/usdot/32.

[6] E. Hollanagel (1998), Cognitive reliability and error analysis method (CREAM). Elsevier.

[7] M.R. Grech, T.J. Horberry, T. Koester (2008), Human Factors in Maritime Domain, CRC Press Taylor \& Francis Group, pp. 152.

[8] UK P\&I Club (1999) "Ten-year trends in maritime risk analysis of major claims - a digest," London.

[9] L. Zhejiang (2001) "Identifying and reducing the involvement of human element in collision at sea," Thesis and Dissertation, World Maritime University, Malmö, Sweden, p. 1.

[10] International Maritime Organization (1997) "Human element vision, principles and goals for the organization (Resolutions A.850(20))," London.

[11] S.G. Kariuki, K. Lowe (2007) "Integrating human factors into process hazard analysis," Journal Science Direct: Reliability Engineering and System Safety 92 pp. 1764-1773.

[12] E. Charniak, R.P. Goldman (1993) "A Bayesian model of plan recognition," Artificial Intelligence 64 pp. 53-79 Elsevier.

[13] M. Marseguerra, E. Zio, M. Librizzi (2007) "Human reliability analysis by fuzzy 'CREAM'," in Risk Analysis 27(1).

[14] A. J. Ross, B. Wallace, J. B. Davies CASP (2003) "Technical note: measurement issues in taxonomic reliability," Safety Science, Elsevier.

[15] Istiarto (2013),"Teori Statistik dan probabilitas", Civil Engineering Faculty, University Gadjahmada Indonesia. Textbook of lecturer. Http://istiarto.staff.ugm.ac.id/docs/statpro/SDP04\%20 Probabilitas.pdf

[16] Haryanti Rivai, Kohei Hirono and Masao Furusho (2012). Quantitative Model of Collision Causes in Japan. The Journal of Japan Institute of Navigation, 127, pp. 125-132.

[17] M.L. Lohberger (2010) "Suggested improvements for ship-installation collision risk models to reflect current collision avoidance systems," Master's Thesis, Faculty of Science and Technology, University of Stavanger, 
pp. 24 .

[18] Cockcroft, A.N. and Lameijer, J.N.F (1972) "A guide to the collision avoidance rules in international. regulations for preventing collisions at sea," 1972 in force 1977, Textbook, Stanford Maritime London.

[19] Japan Captain's Association (2009) "A guide to ship handling" in The Best Seaman Ship, International Mariners Management Association of Japan.

[20] Lloyd Register (June 2009),"Technical matters in a Lloyd's register publication containing case studies covering technical issues and their solutions."

[21] Japan Transport Safety Board (2008) "Marine accident investigations report for fire"

Received 31 December 2012

Revised 11 October 2013

Accepted 22 October 2013 